University of Nebraska - Lincoln

DigitalCommons@University of Nebraska - Lincoln

Ralph Skomski Publications

Research Papers in Physics and Astronomy

2010

Magnetism of core-shell Ti:TiO nanoparticles

Xiaohui Wei

Ralph Skomski

University of Nebraska-Lincoln, rskomski2@unl.edu

Balamurugan Balasubramanian

University of Nebraska-Lincoln, balamurugan@unl.edu

David J. Sellmyer

University of Nebraska-Lincoln, dsellmyer@unl.edu

Follow this and additional works at: https://digitalcommons.unl.edu/physicsskomski

Part of the Physics Commons

Wei, Xiaohui; Skomski, Ralph; Balasubramanian, Balamurugan; and Sellmyer, David J., "Magnetism of coreshell Ti:TiO nanoparticles" (2010). Ralph Skomski Publications. 64.

https://digitalcommons.unl.edu/physicsskomski/64

This Article is brought to you for free and open access by the Research Papers in Physics and Astronomy at DigitalCommons@University of Nebraska - Lincoln. It has been accepted for inclusion in Ralph Skomski Publications by an authorized administrator of DigitalCommons@University of Nebraska - Lincoln. 


\title{
Magnetism of core-shell Ti:TiO nanoparticles
}

\author{
Xiaohui Wei, ${ }^{\text {a) }}$ Ralph Skomski, B. Balamurugan, and D. J. Sellmyer \\ Department of Physics and Astronomy and Nebraska Center for Materials and Nanoscience, University of \\ Nebraska, Lincoln, Nebraska 68588, USA
}

(Presented 21 January 2010; received 31 October 2009; accepted 7 December 2009; published online 5 May 2010)

\begin{abstract}
Ti nanoparticles were produced using a cluster-deposition method. Ti:TiO core-shell structures were fabricated by partially oxidizing the surface of the Ti nanoparticles produced by a cluster-deposition system via multistep annealing at $250{ }^{\circ} \mathrm{C}$ in oxygen. $\mathrm{X}$-ray diffraction and transmission-electron microscopy studies reveal an increase in the thickness of the $\mathrm{TiO}$ shell with increasing annealing time. The magnetic moment and the coercivity of the core-shell nanoparticles increase with the TiO shell thickness, which is consistent with homogenous bulk defects in TiO. The core-shell nanoparticles display an abnormal hysteresis loop, which probably reflects a combination of antiferromagnetic exchange and magnetocrystalline anisotropy. (C) 2010 American Institute of Physics. [doi:10.1063/1.3359423]
\end{abstract}

Room temperature ferromagnetism ${ }^{1}$ has been reported in a group of oxide thin films including $\mathrm{ZnO}, \mathrm{MgO}, \mathrm{TiO}_{2}$, and others. Previous works have focused on uniformly oxidized thin films. ${ }^{1}$ There has not been any report on the formation of metal-metal oxide core-shell nanoparticles during gradual oxidation and the evolution of magnetism during this process. This type of system can provide information on the location and evolution of magnetic moment and exchange coupling mechanism. There are several studies that show the essential role of defects in room temperature ferromagnetic oxides, ${ }^{2-10}$ and $\mathrm{TiO},{ }^{11}$ with $15 \%$ random vacancies on both $\mathrm{Ti}$ and $\mathrm{O}$ sites (or bulk defects), provides an ideal system for investigating defects and magnetism in an otherwise rarely studied nanoparticle material. Fully oxidized rock-salt TiO nanoparticle film has been previously produced with a cluster-deposition system via in situ oxidation ${ }^{2}$ and the film shows ferromagnetism up to $400 \mathrm{~K}$. In this work, we will focus on Ti:TiO core-shell nanoparticles with hexagonal TiO shell.

$\mathrm{Ti}$ nanoparticles were produced using a clusterdeposition method ${ }^{12}$ and deposited on $\mathrm{Si}$ (100) substrates and carbon coated $\mathrm{Cu}$-grids. The as-deposited $\mathrm{Ti}$ nanoparticles were then annealed at $250{ }^{\circ} \mathrm{C}$ in $\mathrm{O}_{2}$ for consecutive $10 \mathrm{~min}$ periods. After each $10 \mathrm{~min}$ annealing period, structural and magnetic properties of the Ti nanoparticles were investigated using x-ray diffraction (XRD) and transmission electron microscopy (TEM), and superconducting quantum interference device magnetometry (SQUID).

XRD patterns of the as-deposited and annealed Ti nanoparticles for different times are shown in Fig. 1. The standard diffraction peaks corresponding to hexagonal $\mathrm{Ti}$ and $\mathrm{TiO}$ structures are indicated as dashed and dotted lines, respectively. The as-deposited sample corresponds to hexagonal $\mathrm{Ti}$ [curve (a) in Fig. 1]. In contrast, after annealing in $\mathrm{O}_{2}$ at $250{ }^{\circ} \mathrm{C}$ for $10 \mathrm{~min}$, the diffraction peak corresponding to the (110) plane of the hexagonal $\mathrm{TiO}$ structure appears along

${ }^{a)}$ Electronic mail: sunshine @ huskers.unl.edu. with a remaining Ti (101) peak [curve (b) in Fig. 1]. The intensity of the $\mathrm{TiO}$ (110) peak increases with increasing annealing time and completely dominates after $50 \mathrm{~min}$ of annealing at $250{ }^{\circ} \mathrm{C}$ [curve (d) in Fig. 1].

The XRD results are consistent with TEM (Fig. 2) analysis. The as-deposited Ti nanoparticles have an average diameter of $27 \mathrm{~nm}$ and clean surface (Fig. 2). However the inset shows the formation of a 5 -nm-thick shell at the surface after 10 min annealing in $\mathrm{O}_{2}$. The Ti core shrinks with increasing annealing time and disappears after $50 \mathrm{~min}$ of annealing.

The magnetic properties of the Ti:TiO core-shell nanoparticles were studied as a function of the annealing time. Figure 3(a) shows a typical hysteresis loop for Ti:TiO nanoparticles (annealed in $\mathrm{O}_{2}$ at $250{ }^{\circ} \mathrm{C}$ for $20 \mathrm{~min}$ ). Note that the paramagnetic background is possibly due to isolated paramagnetic spins. The measured magnetic parameters as a function of the annealing time are summarized in Fig. 3(b). The increase in coercivity $\left(\mathrm{H}_{\mathrm{c}}\right)$ and moment $\left(\mathrm{M}_{\mathrm{s}}\right)$ with the increase in annealing time (or thickness of the TiO shell as verified by TEM and XRD) indicates bulk moment, which is consistent with the bulk defects of TiO.

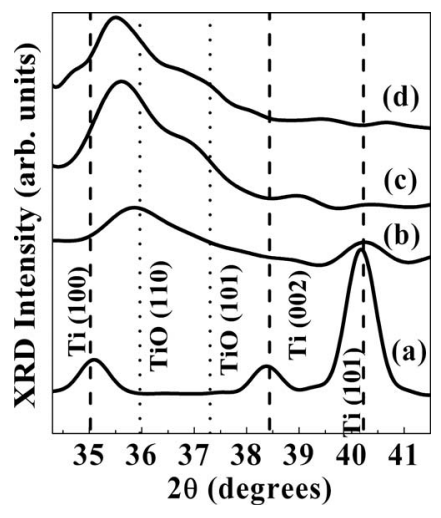

FIG. 1. $\mathrm{Cu} K \alpha$ XRD patterns of (a) as-deposited Ti nanoparticles and Ti:TiO core-shell nanoparticles prepared by annealing of Ti nanoparticles in $\mathrm{O}_{2}$ at $250{ }^{\circ} \mathrm{C}$ for different times: (b) 10, (c) 30, and (d) $50 \mathrm{~min}$. Dotted and dashed lines show the standard peak positions of hexagonal $\mathrm{TiO}$ and hexagonal $\mathrm{Ti}$, respectively. 


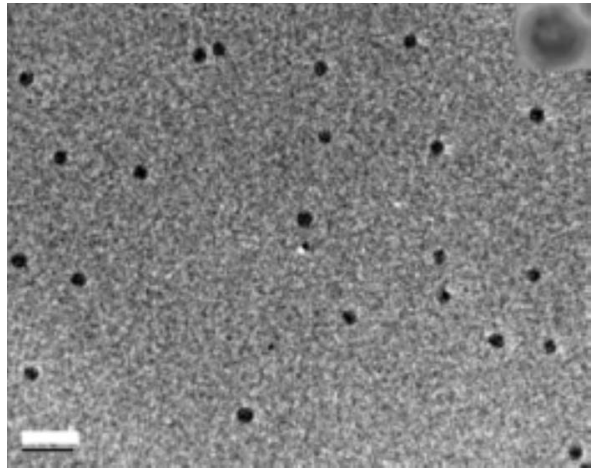

FIG. 2. TEM image of the as-deposited Ti nanoparticles having an average particle size of $27 \mathrm{~nm}$, the scale is $100 \mathrm{~nm}$. The inset shows the formation of the Ti:TiO core-shell structure after annealing the Ti nanoparticles in $\mathrm{O}_{2}$ at $250{ }^{\circ} \mathrm{C}$ for $10 \mathrm{~min}$.

The origin of the magnetic moment in undoped oxides has been attributed to cation ${ }^{5,6,9}$ and oxygen vacancies. ${ }^{5-8}$ Since $\mathrm{TiO}$ is rich in both $\mathrm{Ti}\left(\mathrm{V}_{\mathrm{Ti}}\right)$ and oxygen $\left(\mathrm{V}_{\mathrm{O}}\right)$ vacancies, the exact contribution from each still needs further investigation. Note that, in other oxide thin films without bulk defects, the magnetic moment was attributed to surface defects. ${ }^{2,13}$ The decrease in the moment and coercivity during the last $10 \mathrm{~min}$ annealing is probably due to an annihilation of $\mathrm{V}_{\mathrm{O}}$ (Refs. 3 and 4) or conversion of TiO into a mixture of $\mathrm{TiO}$ and other minority phases.

An interesting feature of the hysteresis loop is a counterintuitive moment jump $(\delta \mathrm{M})$ triggered at a singularity
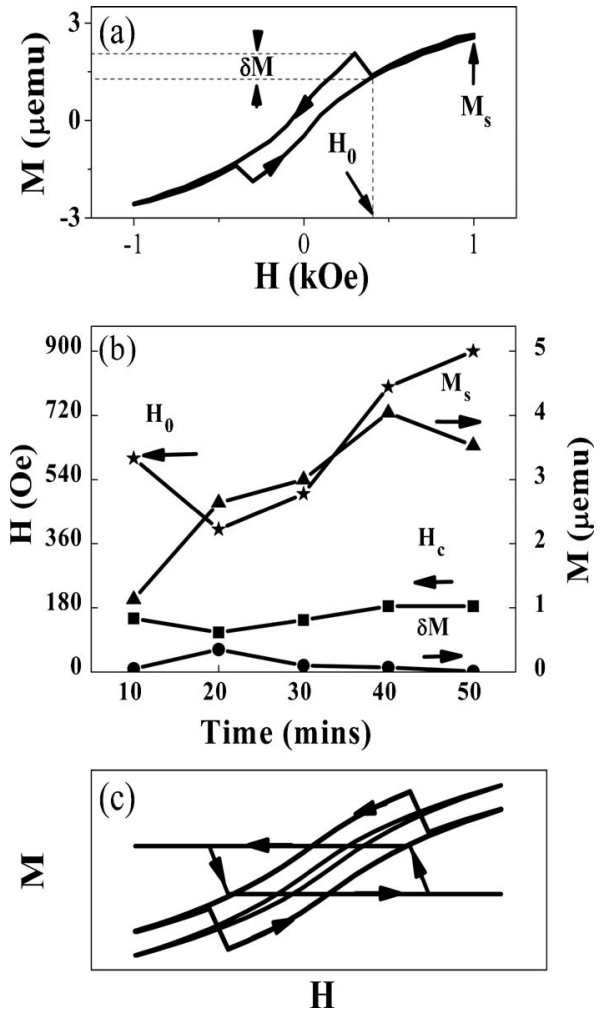

FIG. 3. Magnetic properties of Ti:TiO core-shell nanoparticles: (a) hysteresis loop after the second $10 \mathrm{~min}$ annealing, (b) time dependence of the coercivity $\mathrm{H}_{\mathrm{c}}$ (squares), triggering field $\mathrm{H}_{0}$ (stars), moment $\mathrm{M}_{\mathrm{s}}$ (triangles), and magnetization jump $\delta \mathrm{M}$ (circles), and (c) superposition of a soft hysteresis and a square-shaped loop to produce the abnormal loop. field $\mathrm{H}_{\mathrm{o}}$, as clearly shown in Fig. 3(a). $\delta \mathrm{M}$ increases for the first $20 \mathrm{~min}$ and then, decreases at intermediate annealing steps and is completely absent in the fully oxidized nanoparticles [Fig. 3(b)]. This variation is synchronized with the initial increase and subsequent decrease in the interfacial area (or volume). Thus $\delta \mathrm{M}$ can be correlated with the net moment of unstable interfacial spins. The net moment is originally aligned in a metastable direction against the filed. As field decreases, the spins flip to relatively stable directions resulting in the net moment along the field. This mechanism is illustrated in Fig. 3(c), where the abnormal loop shape can be reproduced by the superposition of a soft hysteresis loop (produced by the $\mathrm{TiO}$ shell) and a square-shaped loop representing the behavior of the interfacial spins. Interestingly, $\mathrm{H}_{\mathrm{o}}$ and $\delta \mathrm{M}$ have opposite variation trends, the origin of which still needs further investigation.

Abnormal moment jump was previously detected in the magneto-optic Kerr effect (MOKE) hysteresis loops of Coimplanted rutile $(001) \mathrm{TiO}_{2}{ }^{14}$ while it was absent in corresponding SQUID hysteresis loops. This was attributed to the sensitivity of MOKE to surface, in-plane anisotropy and transverse components of magnetization. ${ }^{14}$ Interestingly, comparison of the MOKE loops ${ }^{14}$ to ours reveals a similar correlation between $\delta \mathrm{M}$ and $\mathrm{H}_{\mathrm{o}}$. Note that this effect was restricted to the $(001)$ cut rutile $\mathrm{TiO}_{2}$ with fourfold anisotropy and was absent in its (100) cut counterpart with twofold anisotropy. ${ }^{14}$ It is obvious from the MOKE loops ${ }^{14}$ that the effect is more pronounced along the axis, higher symmetry might have favored its observation. Similarly the abnormal moment jump is only observed in our Ti:TiO core-shell particles with hexagonal $\mathrm{TiO}$ shell while it is absent in those with rock-salt $\mathrm{TiO}$ shell. Since the symmetry of anisotropy strongly depends on the crystallographic structure, the hexagonal TiO shell most likely has a sixfold anisotropy as observed in hexagonal Co-doped $\mathrm{ZnO} .{ }^{15}$ Though the exact mechanism leading to the unusual moment jump is unknown, a possible explanation might involve AFM coupling and magnetic anisotropy. The core and shell have different vacancy concentrations and most likely different anisotropies. This combined with an AFM interaction between the core and shell might give rise to the abnormal moment jump. Without magnetic anisotropy, the net magnetization of the AFM coupled system would simply follow the external field, but different sublattice anisotropies may cause sublattice spin jumps in a direction opposite to the external field. ${ }^{16}$ The unusual features in the loops occur at fields of about $0.5 \mathrm{kOe}$, which gives the order of magnitude of the exchange fields. This is consistent with our past analysis of exchange interaction in Co:CoO core-shell structures. ${ }^{17}$ The AFM interactions may be caused by RKKY interactions in the oxide phase $^{9}$ or through the Ti core.

In conclusion, $\mathrm{Ti}: \mathrm{TiO}$ core-shell clusters with increasing shell thicknesses were fabricated by annealing the Ti nanoparticles produced with a cluster-deposition method in $\mathrm{O}_{2}$ at $250{ }^{\circ} \mathrm{C}$ for increasing time. The magnetic moment increases with the growing $\mathrm{TiO}$ shell, consistent with the bulk defects in TiO. The core-shell nanoparticles exhibit abnormal hysteresis loops probably due to magnetocrystalline anisotropies in combination with AFM interactions at the interface. How- 
ever, spin structure and explanation of the magnetization jump needs further experimental and theoretical investigation.

The author would like to thank Z. Sun for his help with the cluster deposition system. This research is supported by NSF MRSEC (Contract No. DMR-0820521) and NCMN.

${ }^{1}$ J. M. D. Coey, Curr. Opin. Solid State Mater. Sci. 10, 83 (2006).

${ }^{2}$ X. Wei, R. Skomski, B. Balamurugan, Z. G. Sun, S. Ducharme, and D. J. Sellmyer, J. Appl. Phys. 105, 07C517 (2009).

${ }^{3}$ R. Schaub, E. Wahlstrom, A. Ronnau, E. Lagsgaard, I. Stensggaard, and F. Besenbacher, Science 299, 377 (2003).

${ }^{4}$ A. Manivannan, G. Glaspell, P. Dutta, and M. S. Seehra, J. Appl. Phys. 97, 10D325 (2005).

${ }^{5}$ R. P. Panguluri, P. Kharel, C. Sudakar, R. Naik, R. Suryanarayanan, V. M. Naik, A. G. Petukhov, B. Nadgorny, and G. Lawes, Phys. Rev. B 79, 165208 (2009).

${ }^{6}$ V. Fernandes, Phys. Rev. B 80, 035202 (2009).
${ }^{7}$ T. Yang, S. Nori, H. Zhou, and J. Narayan, Appl. Phys. Lett. 95, 102506 (2009).

${ }^{8}$ S. D. Yoon, Y. Chen, A. Yang, T. L. Goodrich, X. Zuo, D. A. Arena, K. Ziemer, C. Vittoria, and V. G. Harris, J. Phys.: Condens. Matter 18, L355 (2006).

${ }^{9}$ G. Rahman, V. M. Garcia-Suarez, and S. C. Hong, Phys. Rev. B 78, 184404 (2008).

${ }^{10}$ J. M. D. Coey, K. Wongsaprom, J. Alaria, and M. Venkatesan, J. Phys. D 41, 134012 (2008).

${ }^{11}$ J. Graciani, A. Marquez, and J. F. Sanz, Phys. Rev. B 72, 054117 (2005).

${ }^{12}$ Y. F. Xu, M. L. Yan, and D. J. Sellmyer, in Advanced Magnetic Nanostructures, edited by D. J. Sellmyer and R. Skomski (Springer, New York, 2006), Chap. 8, p. 207.

${ }^{13}$ J. M. D. Coey, J. Appl. Phys. 97, 10D313 (2005).

${ }^{14}$ N. Akdogan, B. Z. Rameev, L. Dorosinsky, H. Sozeri, R. I. Khaibullin, B. Akta, L. R. Tagirov, A. Westphalen, and H. Zabel, J. Phys.: Condens. Matter 17, L359 (2005).

${ }^{15}$ N. Akdoğan, B. Rameev, S. Güler, O. Öztürk, B. Aktas, H. Zabel, R. Khaibullin, and L. Tagirov, Appl. Phys. Lett. 95, 102502 (2009).

${ }^{16} \mathrm{X}$. Wei, B. Balamurugan, R. Skomski, and D. J. Sellmyer (unpublished). ${ }^{17}$ X. Wei, R. Skomski, Z Sun, and D. J. Sellmyer, J. Appl. Phys. 103, 07D514 (2008). 